Journal of Economics and Behavioral Studies

Vol. 6, No. 3, pp. 188-193, Mar 2014 (ISSN: 2220-6140)

\title{
Street Food Vending and Hygiene Practices and Implications for Consumers
}

\author{
R. Kok, R. Balkaran \\ Durban University of Technology, South Africa \\ ronellek@dut.ac.za
}

\begin{abstract}
Street food vending has and is becoming globally a convenient and in most cases an essential service. Lifestyle changes and socio economic factors creates very little space for consumers to look at other alternatives one of which would be to prepare one's own meal. Street food therefore becomes an easy and economic means to acquire prepared food. Safe hygiene practices should become integral to the vendor as the product will be consumed by people of all ages and many may be vulnerable to poor quality food. The street food vendor in turn relies on this service as a means of employment and income generation. The competition between vendors is increased and the pressure to cut corners becomes a reality and one significant corner is appropriate hygiene practices. The practice of appropriate hygiene practices is also as a result of total ignorance of many vendors and the nature of the food that they prepare. The paper explores lessons from various countries in respect of dealing with ensuring good hygiene practices of street food vendors and its usefulness to the South African perspective. One such initiative is the programme launched by the India's Food Safety and Standards Authority and the National Association of Street Vendors of India. South African street food industry is rapidly increasing in size and proportion. Several studies have been undertaken to look at this operation from various perspectives including hygiene practices and small business. Employment creation has become a national imperative of the country and small business development is seen as a significant component to employment creation. This paper sets out to establish the global practices in street food vending from a hygiene perspective and its relevance to the South African context.
\end{abstract}

Keywords: Street food, hygiene, food safety

\section{Introduction}

Street vended foods are interpreted by Von Holy and Makhoane (2006: 89) as "foods and beverages prepared and/or sold by vendors in streets and other public places for immediate consumption or consumption at a later time without further processing or preparation." Globally, street food vending is an omnipresent activity in cities such as Bangkok and Mexico. Street foods can be found in clusters around places of work, schools, hospitals, universities, railway stations, bus terminals and taxi ranks in the urban areas. Not much is known about street food and street food consumption patterns in South Africa even though this forms a large sector of the national economy in terms of providing employment and food sales (Steyn et al., 2011:1). The sale of foods on the street is a common aspect of lifestyle in many countries. Street food vendors are a ubiquitous and conspicuous presence in most cities and they usually have a variety of wares for sale which include snacks, drinks and even full meals. The street food trade has evolved into a large and involved food sector that provides a means of income for the vendors and reasonably priced food to millions of people from all walks of life (Ohiokpehai, 2003: 76). "This industry plays an important role in the cities and towns of many countries in meeting the demands of the city dwellers" (Campbell, 2011:1). The street food sector has been growing rapidly all over the world and South Africa is no exception. It is greatly acknowledged that street foods play a significant socio economic role in terms of employment potential, income for women, and in serving the food at reasonable prices to the lower and middle-income groups and even to the high income groups all over the world (Muzaffar et al., 2009:81).

Lucca et al. (2006:312) has found that "the street-food trade has been reaching new dimensions in developing countries and is recognized as a phenomenon that has great economical and socio-cultural importance." Street food vending is regarded as informal as most vendors businesses are usually not registered. They are small in nature, and are usually run from homes, street pavements or informal arrangements. Campbell (2011:11) states that "There is an assumption that by their nature, street food contamination is inevitable, yet 
millions of people depend on this source of nutrition and economic livelihood. The important contribution that small and micro-enterprises (SMEs) can make to employment and income generation is being recognized worldwide." Martins (2006:18) found that "in South Africa the contribution of these SMEs is particularly significant in view of the fact that the non-agricultural formal sectors downsized by almost a million jobs between 1990 and 2000", which resulted in many unemployed people starting their own informal trading in order to make a living. Martins (2006: 18) explains that "most vendors started with businesses where a relatively small capital layout is needed, such as in street food vending." "Coupled with growing urbanization, these conditions (which are rife in Africa), have combined to give stimulus for the rapid expansion of the street food industry in Africa. At the global level, a World Health Organization survey has shown that street foods make up an important part of the urban food supply of $74 \%$ of the African countries" (Ekanem, 1998:211).

\section{Literature Review}

The hot climate and environmental conditions in South Africa, such as the dusty streets, in which street food vendors are working, provide favourable conditions for bacterial growth. "Food risk is influenced by food type, $\mathrm{pH}$, and method of preparation, water availability, handling, exposure temperature, and holding time" (Campbell, 2011:15). Arambulo et al. (1994: 346) has identified various characteristics of street foods which influence the health risks involved. The characteristics identified include "the type of food product; the nonuse, use, or overuse of food additives; and the nature and extent of microbial or chemical contamination." Nicolas et al. (2007:1) has found that "street food studies carried out in Africa have shown that their unrestricted and unregulated growth have placed a strain on resources in cities. These resources include, water, sewage systems and interferences with the city plan through congestion and littering adversely affecting daily life." The sale of street food is highly argumentative from a health point of view. Bad hygiene practice represents a major threat to consumer health and is a matter of great significance for public health mainly due to improper hygiene practice (Lucca et al., 2006:312). Street food vending can be seen as a source of a wide range of foods that are nutritionally important for different groups of a population (Von Holy and Makhoane, 2006:90). Draper (1996:1) mentions that street foods are processed in many different ways under unregulated conditions. The types of street foods sold differ greatly between countries. However, most meals consist of the staple food served in various forms. In addition, meals such as fried meat, fish and corn meal based ready to eat foods are also prepared and served.

Gordon -Davis (2011:4) interprets hygiene as "the preservation of health and it involves all measures that ensure the safety and quality of food during its handling." Gordon-Davis (2011:4) identifies these measures as "correct storage of both raw and cooked foods as well as correct preparation and cooking methods." Unhygienic preparation of food provides plenty of opportunity for transfer of bacteria as well as growth or survival of bacteria and other pathogens. The hygiene and sanitation aspect is the most significant factor that could possibly have a negative impact on food quality (Gordon-Davis, 2011:4). Mensah et al. (2002: 546) has found that in most countries street food stands are simple structures where running water, toilets and washing facilities are seldom available. The washing of hands, utensils and dishes are often done in bowls or pots of water. Mensah et al. (2002:546) has also mentioned in findings that disinfection is seldom carried out and pests may be attracted to vending sites if there is inadequate sewage disposal. Furthermore, foods prepared at these sites pose health risks as they are ineffectively refrigerated and hygiene principles are not applied properly.

Abdalla et al. (2009: 6967) found that food handling personnel play a significant role in maintaining the safety of food throughout the food production and storage stages. Bad hygienic practices by the vendors may allow bacteria to come into contact with food and cause food poisoning. Failure to maintain equipment and utensils hygienically and in good repair may cause food poisoning. Gordon-Davis (2011:68) has identified the most common food poisoning bacteria as salmonella, staphylococcus aureus, clostridium perfringens, bacillus cereus, Escherichia coli (E.coli) and clostridium botulinum, with salmonella being the most common. Abdalla et al. (2009: 6968) identified that in food processing, food borne microbes can be introduced from infected humans who handle the food, or by cross contamination from some other raw agricultural product and/or the in-plant environment. Abdalla (2009:6968) has identified the hands as the most significant source of transfer for micro-organisms from faeces, face, skin, or other sites to vendors. These micro-organisms such as 
E. coli, Salmonella, Shigella, Campylobacter and S. aureuswho eventually transfer food borne hazards to consumers. For instance, a study done by Arambulo et al in 1994 in Santa Fe de Bogota, Colombia street food vending found that a significant percentage of street food handlers examined were carriers of pathogenic micro-organisms including Staphylococcus aureus, Salmonella typhi, Shigella and salmonella enterifidis. It has been identified by Tambekar et al. (2011:350) that "street foods are frequently associated with diarrhoeal diseases due to their improper handling and serving practice and microbial contamination of ready-to-eat foods sold by street vendors and hawkers has become a major health problem." A study conducted by Aruambulo et al. in the Dominican Republic demonstrated the presence of various bacteria in street foods"including Bacillus cereus, Clostridium perfringens, escherichia coli, and Staphylococcus aureus-as well as a tendency for the bacterial count of street foods to undergo a progressive increase during storage and vending." At many vending sites the serving utensils used are very often contaminated with Staphylococcus sp. which could have possibly been transferred from the vendors' hands in the preparation of food, touching of dish cloths and the water during dish washing and hand washing. This indicates cross contamination between preparation areas, surfaces, dish water and the food which; consequently, perceive a major risk to the health of the public (Tambekar et al., 2011:350).

Estrada-Garcia et al. (2005:1181) found that even though street-vendors in Mexico City provide ready-to-eat food to a large number of consumers "their microbiological status, general hygienic and trading practices were not well known." The study done by Estrada-Garcia et al. (2005:1181) indicated that in the year 2000, "five tianguis (open markets) were visited and 48 vendors in 48 stalls interviewed. A total of 103 taco dressings were sampled for E. coli and Salmonella spp.: (43\%) contained E. coli and (5\%) Salmonella. Both E. coli and salmonellas were isolated from three samples. Of Salmonella-positive stalls $80 \%(4 / 5)$ had three or more food-vendors and $80 \%$ of vendors were males, compared with $37 \cdot 3 \%(16 / 43)$ and $46 \cdot 4 \%(20 / 43)$ in the Salmonella-negative stalls respectively. Food-vendors kept water in buckets (reusing it all day), lacked toilet facilities, and prepared taco dressings the day before which remained at the tianguis without protection for 7 to 8 hours on average." From these statistics Estrada concluded that consumption of street-vended food by local and tourist populations posed a health risk. There is a great need for practical, applied knowledge of hygiene in South Africa, as very few people know about the principle and practices of health and hygiene, and "even fewer are aware of the laws that relate to the handling, transport, and storage of food for public consumption" (Gordon-Davis, 2011:3). "Every year thousands of people in South Africa suffer from food borne illnesses, usually involving severe diarrhoea, vomiting and stomach cramps as a result of eating or drinking contaminated food" (Gordon-Davis, 2011:3). It has also been found by Arumbulo (1994:350) that "in Latin America cholera epidemics has drawn considerable attention to the potential that street food has to transmit disease and has created growing support for attempts to resolve these troubles"

\section{Survey of street food vendors in a Central Durban Transport Exchange}

On $30^{\mathrm{TH}}$ October 2013, a survey of street food vendors was done at a vending site in the city of Durban South Africa. This survey was done in order to obtain a population count of street food vendors in this area for the purpose of a dissertation. Surveys are often used to analyse behavioural patterns and help to identify customer expectations, measure satisfaction levels, and determine specific areas for improvement. The site mentioned above is within the largest transport exchange in the city. Common foods for sale amongst the vendors included beef curry and rice, chicken curry, vetkoek, tripe, sugar beans, fried wors, fried beef and fried chicken amongst many other South African dishes. A total of 29 vendors were observed all of whom said they prepared all their meals on site and began preparation at 5am every day. Washing of utensils was carried out in bowls or pots which were also used for cooking and water was not being changed, as it was not easily accessible. This method of washing meant that water was becoming dirtier and dirtier with repeated use. The majority of the food handlers did not wear gloves, hairnets or aprons. Dirty pots and other dishes were left in heaps close to serving areas and already prepared foods. This caused a great number of flies in the area. Also garbage was left open. Prepared foods were displayed with no covers in very humid weather. Thus encouraging the proliferation of insects and rodents linked to enter disease.

Many of these vendors had plastic chairs and tables' setup with plastic flower arrangements and a variety of sauces for consumers to choose from. It was observed that even with clearly visible unhygienic conditions; consumers would still choose to have a meal at the vending site. This shows that vendors are more concerned 
with the convenience and availability of street foods than in its question of safety. In a study done by Nicolas et al. in 2007 it was observed that "cooked and uncooked foods at warm temperatures for 6 hours or longer without any appropriate holding temperature are a major critical control point of street vending control operations surveyed. In addition cooked foods were subjected to cross-contamination and contamination from various sources such as utensils, knives, raw foodstuffs, flies that sporadically land on the foods, by vendors' bare hand serving and occasional food handling by consumers" This shows that "street food vendors neglect food safety practices, providing to the population unsafe foods."

\section{Public health risks associated with street foods in Durban South Africa}

Ekanem (1998:212) reported that African street foods seem to be a public health hazard because they are prepared and served under unhygienic conditions. In 1998 Ekanem found that very few street food vendors are aware of food safety issues. Street food stalls usually have a limited infrastructure, with restricted access to drinking water, toilets, refrigeration or ice, as well as to hand washing and garbage disposal facilities. Furthermore, Lucca et al. (2006: 312) found that the raw materials are generally of poor quality and stored in unsafe temperatures, for long periods of time. Many street food handlers are ignorant of basic food safety issues. Consequently, street foods are commonly exposed to dangerous abuses, often at all stages of handling. "Products (from the raw material to the finished stage) are often exposed to sources of contamination like soil, dust and sand" (Ekanem, 1998:212). Street food vending is in profusion within the greater Durban area and plays a major role in meeting the food demand of the city dwellers. Popke and Ballard (2004:104) found that "of all the changes to Durban's social and economic space, the increasing prevalence of traders in the city streets is perhaps the most visible." Traders do not obey spatial resolutions, and they seem to show up anywhere in the city, which makes management of their numbers uncontrollable (Popke and Ballard, 2004:100). In Durban, the activities of street vendors disregard the social and moral order, and are thus considered to be tarnishing the city. This kind of equation is of course nothing new. "Images of urban cleanliness and order have long been associated with the activities of its residents, and the sanitation of urban space equated with the 'moral hygiene' of its citizens" (Popke and Ballard, 2004:100).

Von Holy and Makhoane (2006:91) have identified that "some local authorities took the initiative to improve street food vending in their municipal areas." Amongst these municipalities was the Ethekwini Metropolitan Council (formerly called Durban Unicity), located in the KwaZulu-Natal Province. Von Holy and Makhoane (2006:91) found that "after some research into the impact of street food vending within Durban City, the Metro made the decision to integrate the informal economy into its long-term plan to promote its economic development". Some benefits of the informal sector were identified and these include the fact that the informal sector contributes significantly to job creation; it provides convenient service to its customers; and that, it is able to meet religious and cultural needs of the people in the Metro due to its diverse nature (Von Holy and Makhoane, 2006:91). Von Holy and Makhoane (2006:91) indicated that "The Durban Informal Economy Policy, which was developed as a result, provides a strategy that the Metro has aimed to follow in achieving its economic development goals." Today in the Ethekwini Metro street food vendors operate in designated areas, thereby reducing the problem of public nuisance in Durban City. "The Metro ensures that prior to receiving the certificate of acceptability that allows them to operate; street food vendors receive essential food hygiene training, which enables them to comply with minimum hygiene regulations." Ackah et al. (2011:193) found, that a means of regulating street food is for vendors to undergo medical tests. "Some countries insist that food handlers undergo medical screening to test for infectious diseases such as typhoid fever, tuberculosis and cholera and other airborne diseases. Periodic screening is also a requirement by metropolitan, municipal and district environmental health officers and inspectors. The vendors are expected to carry out complete physical medical examination and obtain health certificates issued by the authorized health centres. The health certificate is to be kept by the vendors, presented on inspection and renewed annually" (Ackah et al., 2011:193).

Steyn et al. (2011:1) indicates that microbial studies conducted on street foods in both Bloemfontein and Johannesburg in South Africa have found that "the safety of street foods was better than expected in these two urban areas studied." In his study Steyn et al. (2011:8) found that "two critical points were identified as ensuring best safety of foods including cooking at temperatures over 65 degrees $C$ and having short holding times." The hygiene practices studied in Johannesburg showed that vendors purchased fresh produce from 
retailers daily; prepared enough food for the day and gave away or took left overs home. Steyn et al. (2011:9) found that this practice had an effect on the safe microbial content of the street foods tested but may have had different implications for the people who ate the leftovers. Food safety and standards authority of India chairperson, Mr K. Chandramouli stated that in India, unorganised food operators constitute for $90 \%$ of the total food business operators. Mr Chandramouli further stressed the idea of registration and training of street food vendors and said that the food safety department of every state should have a simple Standard Operating Procedure (SOP) manual and that trained food vendors should adhere to it (National association of street vendors of India). Mr Chandramouli also mentioned that food and health are very much related to each other. "The taste of food prepared by the street vendors is unbeatable and if it is accompanied by hygienic practices then it has no match, even five star hotels cannot beat it" he added.

\section{Conclusion and Recommendations}

Generally street food vendors display the knowledge of food safety and hygiene. This knowledge of food safety can however be improved if a sufficient number of vendors receive training in basic hygiene practices. Vendors must to be aware of hygiene and sanitation aspects of street food vending and consumption. Committees should be established in order to educate vendors and to help street vendors assimilate into the urban food supply chain in the safest and most efficient way possible. One such example is the India's Food Safety and Standards Authority which was established in order to deliver training for people who are actively involved or intend to get involved in preparing food for public consumption, as well as promote general awareness about food safety and food standards. Many sources have stressed the importance of a need for running water and toilets in areas where street vendors operate however, there does not appear to be national data on the food safety aspects of such operations. The aspect of national data of hygiene and sanitation aspects of street food operations should be given consideration in municipality planning since street food makes up a large sector of the informal economy of South Africa. With great possibility that the sale of street food could increase consideration should be given to possible ways that the practice can be done in a hygienic and safe manner.

Many studies done have shown that street food vendors have sufficient information regarding hygiene and food safety principles and they are aware of the need to ensure safe practices in preparing foods for public consumption. The practices examined in these studies also indicate that street food vendors can provide food of good quality if emphasis is placed on hygienic practices and regulatory compliance; therefore training can be regarded as crucial in ensuring food safety. South African government should accept the need to regulate and institutionalize street food vending in a way that will structurally develop it and allow for application of measures dedicated to nurturing hygienic conditions and ensuring safe food for the consumer. Such reformation should be encouraged by initiatives already taken by certain countries-including Singapore and India. These regulations should create a favourable base from which to guide street food vending along a more beneficial and productive path. As mentioned earlier, street food vending plays an important role in the South African economy, hence, there is a profound need to apply new strategies that will permit currently illegal street food vending activities to be reorganized and to gain official recognition. This process should lead to adoption of measures designed to improve the hygienic conditions under which street food is sold, so as to ensure an adequate level of safety for the consumer. The new norms and regulations should emphasize the need for changes in consumer and street vendor attitudes based on equally necessary changes in their understanding of personal hygiene and food safety must be remembered that the basis for altering the present situation in the desired manner will be provided by training, education, and communication.

\section{References}

Abdalla, M. A., Suliman, S. E. \& Bakhiet, A. O. (2009). Food safety knowledge and practices of street food vendors in Atbara City (Naher Elneel State Sudan). African Journal of Biotechnology, 8, 6967-6971.

Ackah, M., Gyamfi, E. E., Anim, A. K., Oseil, J., Hansen, J. K. \& Agyemang, O. (2011). Socioeconomic profile, knowledge of hygiene and food safety practices among street food vendors in some parts of AccraGhana. Internet journal of food safety, 13, 191-197.

Arambulo, P., Almeida, C., Cubblar, S. \& Bellotto, A. (1994). Street Food Vending in Latin America. 
Campbell, P. T. (2011). Assessing the knowledge, attitudes and practices of street food vendors in the city of Johannesburg regarding food hygiene and safety. School of Public Health, University of the Western Cape.

Draper, A. (1996). Street foods in developing counties :The potential for micronutrient fortification London School of Hygiene and Tropical Medicine.

Ekanem, E. O. (1998). The street food trade in Africa: safety and socio-environmental issues. Food Control, 9, 211-215.

Estrada-Garci, T., Lopez-Saucedo, C., Zamarripa-Ayala, B., Thompson, M. R., Escobar-Gutierrez, A., ManceraMartinez, A. \& Gutierrez-Cogco, L. (2004). Prevalence of Escherichia coli and Salmonella spp. in street-vended food of open markets (tianguis) and general hygienic and trading practices in Mexico City,132, 1181-1184.

Gordon-Davis, L. (2011). The Hospitality Industry Handbook on Hygiene and Safety for South African Students and Practioners South Africa, Juta \& Company Ltd.

Jeffery Popke, E. \& Ballard, R. (2004). Dislocating modernity: Identity, space and representations of street trade in Durban, South Africa. Geoforum, 35, 99-110.

Lucca, A., Da Silva, T. \& Ferraz, E. A. (2006). Street-food: The hygiene conditions of hot-dogs sold in São Paulo, Brazil. Food Control, 17, 312-316.

Martins, J. H. (2006). Socioeconomic and hygiene features of street food vending in Gauteng. South african journal of clinical nutrition, $19,18-25$..

Muzaffar, A. T., Huq, I. \& Mallik, B. A. (2009). Entrepreneurs of the Streets: an Analytical Work on the Street Food Vendors of Dhaka City. International Journal of Business and Management, 4(1), P80.

NASVI (National association of street vendors of India). (2013). Sustaining food security from the streets Mass training of street food vendors on food safety and hygiene [Online]. India. [Accessed 9 january 2014].

Nicolas, B., Razack, B. A., Yollande, I. \& Aly, S. (2007). Street-Vended Foods Improvement: Contamination Mechanisms and Application of Food Safety Objective Strategy : Critical Review. Pakistan Journal of Nutrition, 6, 1-10.

Ohiokpehai, O. (2003). Nutritional aspects of street foods in Botswana. Pakistan Journal of Nutrition, 2, 76-81.

Steyn, D., Labadarios, L. \& Nel, J. (2011). Factors which influence the consumption of street foods and fast foods in South Africa-a national survey. Nutrition Journal, 10, 2-10.

Tambekar, D. H., Kulnari, R. V., Shirsat, S. D. \& Bhadange, D. G. (2011). Bacteriological quality of street vended food Panipuri: A case study of Amravati city (MS) India. Bioscience Discovery, 2, 350-354.

Von holy, A. \& Makhoane, F. M. (2006). Improving street food vending in South Africa: Achievements and lessons learned. International journal of food microbiology, 111, 89-92. 